INDEPENDENT JOURNAL OF MANAGEMENT \& PRODUCTION (IJM\&P)

http://www.ijmp.jor.br V. 12, n. 6, Special Edition ISE, S\&P - November 2021

ISSN: 2236-269X

DOI: 10.14807/ijmp.v12i6.1748

\title{
INCREASING THE EFFECTIVENESS OF FOOD SUPPLY CHAIN LOGISTICS THROUGH DIGITAL TRANSFORMATION
}

\author{
Kristina Sermuksnyte-Alesiuniene \\ Lithuanian Centre for Social Sciences; Institute of Economics and \\ Rural Development, Lithuania \\ E-mail: kristina.alesiuniene@gmail.com \\ Zaneta Simanaviciene \\ Mykolas Romeris University, Lithuania \\ E-mail: zansim55@gmail.com \\ Daiva Bickauske \\ Mykolas Romeris University, Lithuania \\ E-mail: daiva.biskauske@gmail.com \\ Stefaniia Mosiiuk \\ National University of Life and Environmental Sciences of Ukraine, \\ Ukraine \\ E-mail: 4stefani2@gmail.com \\ Iryna Belova \\ West Ukrainian National University, Ukraine \\ E-mail: ire@ukr.net \\ Submission: 8/2/2021 \\ Accept: 9/14/2021
}

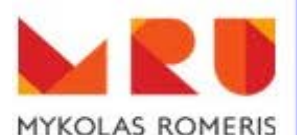
UNIVERSITY

\section{ABSTRACT}

During the COVID-19 crisis, there were many restrictions to transportation. Due to that, a significant disruption in the food supply chain has emerged. The transportation of the fresh food and maintaining the quality, from farm to the table or distributing and then collecting from the warehouses and delivering to the consumer, has become crucial. Technologies and especially IoT, have become the primary tool to fight it. The research objective is to analyze and create new knowledge about digital technologies used to improve and make more effective the food supply chain processes. An exploratory case study methodology helps to investigate a large consortium based on IoT technologies, implemented in pilot cases on farm level and measuring their performance over the period of four years. This is an interpretative study, and the method of semi-structured interviews and document review for collecting the data was used. 
DOI: $10.14807 /$ ijmp.v12i6.1748

The results show IoT-connected sensors and systems in food and beverage supply chain logistics offer real-time visibility and data-driven analytics, allowing stakeholders to improve performance, cut operating costs, conduct predictive maintenance to avoid downtime, and even decrease energy usage or reduce negative environmental impacts.

Keywords: agriculture; digitalization; digital technologies; IoT; logistics; supply chain; effectiveness

\section{INTRODUCTION}

The European Green Deal (2020) sets out how to make Europe the first climate-neutral continent by 2050. It outlines a new, sustainable and inclusive growth strategy aimed at improving people's health and quality of life, boosting the economy, caring for nature and leaving no one behind. The strategy of Farm to Fork is at the heart of the Green Deal. It addresses the challenges of sustainable food systems and seeks to ensure a sustainable livelihood for primary producers who are still lagging behind in terms of income, which is essential for the success of the recovery and the transition.

Given the complexity and the huge number of actors involved in the food value chain, the crises such as the Covid-19 affect the food chain in different ways. Although there has been sufficient food supply in general, this pandemic has presented many problems, such as logistical disruption of supply chains. In today's intensely competitive global marketplace, businesses' pressure to find new ways to create value and offer it to their customers is growing ever stronger. The growing need for the industry to compete with its goods in a global economy across cost, quality, and service dimensions has contributed significantly to the need to develop a more efficient logistics system.

Technology has been completely revolutionizing the present era, and digitalization can bring new opportunities for companies by improving the whole value chain (Kilimis, 2019). The agricultural sector is no exception. Digital transformation can bring new opportunities for agri-food companies and open up new growth paths for development. One of the most significant contributions to future sustainability would come from a radical transformation of the agriculture and food (agri-food) value chain (CEPS, 2019). 
DOI: $10.14807 /$ ijmp.v12i6.1748

\section{LITERATURE REVIEW}

\subsection{Digital Transformation of the Agri-food sector}

The applications of digital solutions in the agri-food sector are very diverse. It can help extend shelf life, monitor freshness, display information on quality, improve safety, and improve convenience. Rotz (2018) emphasizes the technical and organizational challenges of digitalization in the agri-food. Lack of awareness, especially among the rural farmers, low level of digitalization of agri-food companies, and low incomes of rural farmers, together with high costs of ICT infrastructure, insufficient personnel to handle ICT facilities, and the absence of local content of language on internet are making digital transformation a challenge (Salampasis, 2013).

Many problems exist throughout agriculture, such as irrigation, the use of pesticides, fertilizers, the monitoring of crops, land and livestock (López-Morales, 2020). Potential applications of ICT solutions in agri-food are very diverse, including, among others, software for supply chain or financial management, mobile applications for farm management, agricultural land use optimization, precision agriculture applications and other which fall into other categories of ICT-enabled services (Salampasis, 2013).

Motivated by digital transformation, the agricultural sector is offering its farms with new services and devices (drones and satellite images, sensors, actuators, weather information) to optimize resources, increase efficiency and at the same time reduce the effect on the environment. (López-Morales, 2020).

Digital transformation can significantly contribute to the improvement of products and/or services and management of operations in a more efficient way. It can also trigger costs reduction or can help to gain a competitive advantage in the market. Ulas (2019) pointed out several driving factors expediting digital transformation: globalization, advancement of technology and innovation, electronic commerce, and social media. The idea of an interconnected world has also gained attention from the industry sector, and the vision of the digital revolution is emerging, popularly known as Industry 4.0 (Kang, 2016).

Experts highlight four areas for which digitization technologies will have the most significant impact: productivity, revenue growth, employment, and investment (Russmann et al., 2015). The development of Industry 4.0, artificial intelligence, Internet of Things (IoT), blockchain, cloud computing, augmented reality, 3D Printers, chatbots, Big Data, and nanotechnology have been speeding up the process of digitalization. 
DOI: 10.14807/ijmp.v12i6.1748

"Digital agricultural revolution" is a new term explaining the changes as the Agri-food industry's traditional approach is undergoing a fundamental transformation. As stated by Schwab (2016), no doubt, it offers significant opportunities through the availability of highly interconnected and data-intensive computational technologies as part of Industry 4.0.

\subsection{The role of logistics in the Agri-food sector}

The term "logistics" could be interpreted in many different ways. Various authors emphasize on different aspects of its definition. Logistic is the core of production and marketing organization (Movahedi et al., 2009). The quality of marketing depends on how the products are delivered to the final customer. The value of logistics for the agri-food industry has become more widely recognized by organizations worldwide.

Agri-food logistics is an important part of the economy and an interconnected system that controls, coordinates, and organizes different flows of logistics, ranging from production through points of storage, processing, and trade to the final consumer. The aim is to provide the final consumer with uninterrupted supplies of safe food products with minimum logistics costs and under environment-friendly conditions (Wajszczuk, 2016).

When it comes to agricultural logistics, we need to look more broadly and include the supply chain concept. Supply chain management is a core component of the performance of companies' value chains (Hult, 2007). Supply chain management is the management of trading off products and information in the logistics process of companies ranging from sourcing raw materials to delivery to the customers (Felea, 2013).

The supply chain includes a substantial number of manufacturers, suppliers, and consumers and is undoubtedly responsive to the complexities of the supply chain. Subsequently, it is one of the key concerns in the supply chain management sector (Emamisaleh, 2018). Logistics is a supply chain activity that plans, implements, and manages the reliable, efficient transportation and storage of products, services, and information to meet consumer needs, services, and related information to meet consumer needs (Croom, 2018).

Whereas logistics is an integral part of supply chain management, it provides the most important link between the manufacturer and the customer and could be defined as the movement of products and goods from the manufacturer or supplier to their final customer. The supply chain comprehends all of those activities concomitant with stirring goods from the raw-materials phase through to the end-user (Bertodo, 2002). 
The successful performance of agriculture depends on ensuring the proper supply of agricultural products to the appropriate market. Over the last years, supply chain management has presumed a noteworthy role in a firm's performance and has attracted thoughtful research attention (Jain et al, 2010).

In the current turbulent times, agricultural enterprises' logistics is affected by globalization and the dynamic growth of new technologies. Supply chain management is quite complex and involves several aspects and viewpoints, all of which have an ultimate objective: to deliver the finished product to the client as quickly as possible and at the lowest cost possible.

Supply chain management comprises a multifaceted set of systems and processes, including procurement and procurement, product design, product development, collaborative planning, forecasting, replenishment, and distribution (Chen, 2004). Successful and efficient implementation of these systems is essential for efficiency and performance and sustainable competitive advantage. Supply chain management is well defined as a set of processes or activities undertaken in a firm to facilitate its supply chain's operational management (Ibrahim, 2014).

Researchers had identified six dimensions of supply chain management comprehensive literature review and integration activities: strategic supplier partnerships, relationships with clients, sharing of quality information, operational lean practices but also postponement (Mogaka, 2020). Considering agri-food business, supply chain management means reach agro products to the market in time.

\subsection{Main challenges of logistics in the agri-food sector}

The field of supply chain processes and logistics for agriculture and food produce is to some degree, unpredictable. Over time, the supply chain mechanism for such products has grown into an increased chain of facilities, such as in-time deliveries, centralized specialized manufacturing processes, and the maintenance of low loading rates. Agri-food companies produce raw materials for agricultural processing and fresh products, which are delivered to the consumer directly or indirectly.

The quality of raw materials, products and the costs generated by agri-food companies enterprises will have a significant impact on the efficiency of the entire supply chain. Due to the direct interaction with the environment and living organisms, the type of production technologies and logistics will affect these costs and quality (Wajszczuk, 2016). 
Mathur (2018) specified if a company can start measuring customer satisfaction related to what a supply chain can do and also link customer satisfaction in terms of profit or revenue growth, then you can attach customer values to profit and loss, and even to the balance sheet".

Essential success elements for retailers and manufacturers are the efficiency of the logistics and the technology used. The entire process needs to be controlled effectively to ensure that correct product(s) are delivered, to the right location, in the proper condition, within a reasonable period of time while maintaining cost efficiency for all parties involved. It is essential to highlight the maintenance and spare parts and tools, specifically among the supply chain activities. In a nutshell, the challenges to meet are a quick and reliable delivery of the spare parts inventory at minimum costs (Lozano, 2017).

Wajszczuk (2016) summarizes the many studies conducted, identifies that the main challenges related with logistics are the issue of receiving aligned-quality goods from various small farmers, different sources of supply of raw material batches, contamination issues, the presence of numerous and independent links in the entire supply chain, formation of very long marketing channels, where an unequal balance of power appears in the supply chain, poor infrastructure and limited access to the required means, difficulties in establishing horizontal farm cooperation, mainly due to the lack of trust, mostly in developing countries (the lack of proven business models, modern storage infrastructure, ICTs, etc.).

The sustainability of the supply chain has been investigated from various dimensions (Beske, 2014). Companies are being impacted by multiple factors, as government initiatives, stakeholders, and customers to apply sustainable supply chain initiatives (Varsei, 2014). Moving toward sustainability is essential. Due to the existence of pressures derived from the environment forcing agri-food companies to followed sustainability standards, they need to be committed to sustainable thinking (Emamisaleh, 2017). McKinnon (2012) emphasizes the importance of optimizing vehicles' use as a very effective improvement for sustainability, creating both environmental and economic benefits. Thus, the pursuit of sustainability is a significant challenge for agri-food companies.

\subsection{Measuring the effectiveness of the logistics system}

The assessment of the logistics system's effectiveness plays a crucial role in the performance of the physical distribution of products and businesses' smooth running (Oettmeier, 2016). A very common problem concerning the logistics system design is that 


\section{INDEPENDENT JOURNAL OF MANAGEMENT \& PRODUCTION (IJM\&P)}

http://www.ijmp.jor.br

v. 12, n. 6, Special Edition ISE, S\&P - November 2021

ISSN: 2236-269X

DOI: $10.14807 /$ ijmp.v12i6.1748

projects lack a well-structured framework for analysis. As a result, oversophisticated systems that are not responsive to the market and business environment changes are developed.

Every logistics system has a clear goal: to collect and efficiently ensure a timely movement of supplies, goods, and equipment to the requested locations at a rational cost (Hall, 2008). Effective logistics management helps optimize the current production and distribution processes and significantly reduce costs and improve services (Rushton, 2014).

In general, the ratio between the profits and the costs arising from the supply chain helps to evaluate the efficiency of the logistics system. Elements such as the aggregate costs of logistics, the level of logistics service quality, the performance of the business system, the overall duration of the logistics processes in the system, and its quality (logistics services' level) are common KPIs or key performance indicators for any logistics system (Tyapuhin, 2007).

The latter ones are widely used in the comparative evaluation of business entities and their logistics systems, and, as such, they are measurable. Moreover, these KPIs are the backbone of the planning of operations, tactics, and strategies of modern companies and the monitoring of the effectiveness of the logistics system and business entity's management accounting system.

Elements such as transportation costs, storage costs, goods-processing-affiliated costs, inventory management costs, order management costs, costs related to the exploitation of logistics information systems, stock's formation costs, and raw material maintenance costs, finished products' costs, the costs of potential damages arising from the manifestation of the logistics risks or from the insufficiency of logistics services comprise a general classification of logistics costs by functional areas (Arshinina, 2020).

To continue with it, the evaluation of logistics services quality is a necessary undertaking that is evaluated directly during its provision. Also, it is important to place the logistics services on a high-level corresponding with the potential consumer's needs. To sum up, the extent of congruity between the logistics system's consumer expectations and the actual level of this service's provision defines the logistics services' quality. The level of logistics service provision is expressed through a set of quality criteria such as the physical environment of the service, consumer behavior, the reliability of the logistics service provider, responsibility, maturity of the service, and security (Tyapuhin, 2007).

Logistics system resources are the inputs, whereas the outputs reflect the results, and the quality of all logistics services depends on their structure, quantity, and composition. For 
DOI: 10.14807/ijmp.v12i6.1748

this reason, it is necessary to assess the accuracy of the time and the place of delivery, range and the quantity of products supplied, quality indicators, products supplied, and compliance with the prices on the market so that we could formalize the procedure on how to evaluate the efficiency of logistics.

\section{DATA AND METHODOLOGY}

\subsection{Research methodology}

Applying technologies to any parts of the food supply chain finally enables stakeholders to collect and analyze the data, which previously was not accessible. The result becomes the foundation for further improving existing agri-food value chain logistics processes and creating new ones. The Internet of Things (IoT) technology is one of the crucial elements of effective logistics in any industry (Da Xu, 2014). The rising usage of smart sensors, smart carry bar codes, different tags, enabling precise, real-time tracking through the entire food supply chain - are good examples of how IoT makes logistics more effective.

The purpose of this paper is to analyze the role and impact of digital technologies, the IoT in particular, in logistics of the food supply chain and underline what is the effectiveness of logistic system when the technology is applied in real-world conditions.

The research objective is to analyze and create new knowledge about digital technologies used to improve and make more effective the food supply chain processes. An exploratory case study methodology helps to investigate a large consortium based on IoT technologies, implemented in pilot cases on farm level and measuring their performance over the period of four years. The paper seeks to understand better and provide insights on how digital technologies, IoT in particular, in logistics are being used to bring more value to the food supply chain.

This is an interpretative study, and the method of semi-structured interviews and document review for collecting the data was used. Experts on the agri-food sector's digitalization were selected. They had no less than ten years of experience working with digital innovation technologies, tools, creating the products, implementing them into the market, and making analyses. At least five experts were selected who directly took part in employing the IOF2020 project. A total number of 15 interviews were conducted. The different analysis methods of final data were implemented to reach the paper objective.

\subsection{Collected empirical data}


DOI: 10.14807/ijmp.v12i6.1748

Referring to the IoT in the agri-food sectorial context means that particular layers of the system, usually three (device, network, and application) are applied (Villa-Henriksen, 2020). Such application enables gathering data from each step of the agri-food supply and value chain processes. IoT technologies are considered the most important digital innovations that influence the biggest amount of valued data collection in the agri-food sector (Tzounis, 2017). It is expected that by 2050, IoT technologies have the biggest potential to increase agricultural productivity by $70 \%$, for example, achieving higher crop yields with less cost, improve the nutritional value of the food significantly, in livestock improve care quality and herd productivity (Sarni, 2016).

A significant amount of food in many cases is wasted due to logistics problems. The most significant loss occurs during transportation and storage. In total, it is over $20 \%$ of the world's food production. IoT solutions applied to the food supply chain can reduce this number by $10-15 \%$ (PWC report, 2016).

During the COVID-19 crisis, there were many restrictions to transportation. Due to that, a significant disruption in the food supply chain has emerged. The transportation of the fresh food and maintaining the quality, from farm to the table or distributing and then collecting from the warehouses and delivering to the consumer, has become crucial. Technologies and especially IoT, have become the primary tool to fight it.

Digitalization of the agri-food sector is one of the priorities moving towards the EU's twin transition. The Commission has approved various large-scale projects to accelerate digital innovations into the sector. During five years, a vast number of various use cases have been approved and successfully applied in everyday food supply and value chain processes. Usage of sensors, smart planning, smart animal health monitoring, plant diseases monitoring systems, etc., are helping farmers to continue their daily operations while reducing their environmental impact and maintaining their competitiveness in the market. EU funding has laid a solid foundation for such possibilities and solutions to be commercialized and available to the market.

IoF2020, DEMETER, ATLAS, and SmartAgriHubs are four large-scale piloting initiatives that have secured a total of $€ 80$ million for research and innovation into the application of emerging technologies for the agricultural sector. IoF2020 was founded in January 2017 to promote the IoT in the food and agriculture industries. This initiative, which has received a €30 million investment, puts together two ecosystems - agribusiness and 
DOI: 10.14807/ijmp.v12i6.1748

advanced ICT suppliers - that have boosted digital innovation in agriculture. This is why the IoF2020 has been chosen as a use case to analyze.

The IOF2020 project's main objective is to set a strong foundation for implementing IoT technology in agri-food to provide safe and healthy food, help farmers stay competitive, and increase the competitiveness of the food supply and value chain in the EU. The project's main result is the consolidated EU leading position in the global IoT industry. It has created a healthy ecosystem through the whole food value chain: farmers, the food industry, technology providers, and research institutes. Led by the number one in agri-food research Wageningen UR University, IoF2020 was joined by 73 partners, acting in $22 \mathrm{EU}$ member states. It is by no means the biggest pilot-project of its kind.

There are 19 use cases divided into five types of trials: Arable, Dairy, Fruits, Vegetables, and Meat. The pilot's purpose was to demonstrate the use of innovative digital IoT solutions for a vast number of application areas.

The project has taken a multi-actor approach choosing key performance indicators (KPI's) closely related to user acceptability, stakeholder engagement, sustainable business models, new components improving the technology and market readiness levels. These factors are significant in analyzing the effectiveness of the logistics of the food supply chain.

In general, KPI is a value that indicates the degree to which a strategic goal has been accomplished. In selected pilot use cases, KPIs are used to determine if established goals have been met at different levels. Each use case measures the effect of the IoT solution on various industries, business priorities, and society at large. Consequently, primary success metrics show observable performance in meeting the critical market goals.

In the scope of IoF, three levels of KPIs are indicated: operational (number of sensors installed, number of farmers participating, number of ICT component used), strategic (yield increase, efficiency, improved market access, less water use, work time efficiency, etc.) and visionary (less $\mathrm{CO} 2$, user satisfaction, work stress reduction, farmers' livelihood, etc.). For the analysis, strategic and, in some cases, visionary KPIs have been considered.

A well-coordinated distribution plan for use case results and project learnings, backed up by customers and consumers, guarantees a high degree of business exposure and a quicker learning curve. As a result of IoF2020, data-driven farming, autonomous operations, virtual food chains, and personalized nutrition for European citizens are now feasible. 
The pilot use cases demonstrated solid results on IoT technologies; for example, on an average farm using IoT, the yield rises by 3.75\%, and energy costs drop 27 to 36 euros per hectare, while water use for irrigation falls by $12 \%$.

Based on the experts' suggestion, the most suitable for analysis pilot cases in agri-food supply chain logistics based on IoT technology was chosen. They were selected from three areas of trials: Arable, Fruit/Vegetable, Beverage. According to experts, these are some of the most important areas where the food supply chain logistics must be effective and sustainable.

\subsubsection{The internet of things and logistics in arable farming}

\subsubsection{General information of Traceability for Food and Feed Logistics use case No.1} (UC.1)

The implemented pilot project's main objective is traceability of food and feed logistics. The use case has developed a smart system that ensures adequate feed logistics and maximum traceability of the distribution process. It incorporates a revolutionary method that secures and authenticates the transportation of the goods in the agri-food chain, ensuring that feed and food are shipped without fear of losing quality and being contaminated. For the capability to control and monitor such a process in a healthy and traceable procedure for their goods before they leave the factory, producers of animal feed and human food devote a significant amount of time and money.

The use case has overtaken the task to provide the system that can control the goods' transport and delivery to the customer's silo or warehouse. It has provided an additional management system to ensure that these items are shipped and distributed correctly. As a result, it highly eliminates the possibility that products will be shipped to the incorrect storage or polluted and spoliated and cause harm to the consumer.

An integrated IoT-based automatic storage detection system can ensure that the proper merchandise is shipped, as well as keeping track of its transportation and registration information. The use case demonstrates that the whole procedure is entirely traceable, and the possibility of pollution is reduced.

\subsubsection{The impact made by the technology in the UC.1}

In this case, logistics in the food supply chain addresses essential food safety issues and sustainability requirements while increasing productivity and significantly rising user satisfaction. The target group of the users was animal feed and bulk-goods buyers. 
DOI: 10.14807/ijmp.v12i6.1748

Nevertheless, the use case has targeted farms, consumers, supply chain managers, warehouse/silo owners directly.

The increase in consumer trust in food delivery and the availability of sufficient knowledge to make food choices reflect consumer satisfaction. This data was structured, analyzed, and shared with customers and other stakeholders.

Consumer trust is one of the crucial factors in the food supply chain, so the IoT technologies in the use case were projected to solve that. Consumer confidence in food on the market can be strengthened, and this particular use case with the application of the IoT tool has proved this.

\subsubsection{Supply chain management in the UC.1}

This particular use case has an obvious supply chain process, which needs to be improved in management. The crucial role here plays the relations with clients, strategic supplier partnerships, and of course, the sharing of quality information.

The supply chain starts at the silos/warehouses level and continues to the end-users. In between, some processes could affect the final delivery result. Controlling and monitoring such processes as trailer equipment and loading procedure, silo device, and the unloading procedure is essential.

The possibility to share accurate information with drivers, logistics managers, consumers - creates added value. Operating such data brings different value propositions to different stakeholders. For example, a farmer gets the transparent process, which requires less paperwork and is equipped with online monitoring and digital signature. It helps with the easy delivery of the right food to the right animal.

The transport manager enjoys less paperwork and holds data on which exact quality bulk-goods are being delivered, and tracks the trailer's exact location. For the driver of the trailer, the automatization means reliability in the process and less human error, and on such times as COVID-19, it makes a human contact-free process.

The measurable value created for the customer: significant reduction of the risk of wrong warehouse or silo delivery up to $90 \%$, which helps maintain good quality relations with the clients. Overall the logistics controlled by such a system become leaner in management processes.

\subsubsection{Logistics food supply chain challenges solved in the UC.1}


DOI: 10.14807/ijmp.v12i6.1748

The use case significantly contributes to solving logistics' main challenges in the agrifood sector. The implemented system tends to reduce the risk of animal feed contamination up to $20 \%$ and reduce human food contamination up to $22 \%$.

When the food during the handling and transportation gets polluted, it increases food waste. In many cases, the cleaning processes can be applied, nor is it possible to clean to the point that it would gain previous quality back. So, the reduction of waste by contamination is also an important value proposition created by the use case. Simultaneously, increased security of bulks goods delivery is observed, which lowers the lack of trust in the whole supply chain.

The food supply chain stakeholders are provided with the possibility to trace the food and its quality up and down the supply chain. Improved traceability up to $25 \%$ is expected using the system.

\subsubsection{Measured effectiveness of the food supply chain in the UC.1}

Performance and the impact of the use case overall consists of all the value propositions which arise from it: reduce risk of animal and human feed contamination, reduce waste by contamination, improve traceability, increase the security of bulks goods delivery. Measuring the effectiveness, it is important to underline the reduction of recovery costs and reduce additional transport compared to the usual logistic process. Moreover, the increase of user satisfaction using IoT systems on silo devices is 7.9 (on the scale from 0 (not satisfied) to 10 (extremely satisfied)) and on trailer equipment 7.65 (on the scale from 0 (not satisfied) to 10 (extremely satisfied)).

Real-time data distribution and tracking of all trailers, secure delivery procedures via traceability from the factory to customer, accurate monitoring of the discharging process, direct warning in the event of anomalies during deliveries, data collection for analysis and prevention, and enhanced food safety all contribute to a new and easily measurable value in the food supply chain.

Overall, the use case demonstrates improvement in the business system's performance, rising user satisfaction, and service quality. Furthermore, it reduces the cost of recovery and transport.

\subsubsection{The internet of things and logistics in fruit supply chain}

\subsubsection{General information of Intelligent Fruit Logistics use case No.2 (UC.2)}


The IoT-based tool enables traceability of trays, anti-theft functionality, and temperature monitoring. The system connects different parts of the fruit supply logistics: the farm production, processing industry, transport, and finally retailer and end-consumer.

Since the fruits and vegetables are perishable, returnable transport items (RTI) are essential in bringing products to the market. Millions of different kinds of RTIs are used daily, both in and outside the supply chain. These stakeholders feel an urgent need to remove inefficiencies to assure product quality and security while protecting company assets.

\subsubsection{The impact made by the technology in the UC.2}

It was discovered that the method could go beyond simply being a monitoring and tracking system. It can also collect data, store it, and retrieve when needed. The amount of collected data can be vast and overwhelming in detail. However, the system can quickly analyze complex value chains or commodity flows and deliver the output simply and understandably.

As a result, by relieving pressure on supply chains or commodity flows, the approach positively impacts sensitive market situations. Customers can receive a single project-based implementation and end-user training to help them use the innovative trays independently. Customers and the entire supply chain need to know where those assets are at any given time. It is crucial to consider the number of RTIs required during peak harvesting seasons versus the number required during the quieter winter months.

Using closed scenarios and targeted data provides a more precise and informative analysis and evaluation. So IoT technology contributes to gathering the big data that was missed out and analyzing it and provides results that can contribute to optimizing everyday business planning processes.

\subsubsection{Supply chain management in the UC.2}

The system enables players to see issues across the supply chain by providing information on bottlenecks, thereby facilitating pinpointing opportunities for expansion, developing new processes, analyzing trends, and increasing the supply of raw materials efficiency. So, the quality information and its analysis are making a big difference for the stakeholders.

All along the line, there is a tremendous potential for increasing management effectiveness of the supply chain and finding bottlenecks or any other problems at an early 
DOI: 10.14807/ijmp.v12i6.1748

stage, which attributes to maintaining the best possible partnerships with suppliers and clients and creating new ones based on efficient management of processes.

\subsubsection{Logistics food supply chain challenges solved by the UC.2}

RTI flow lacks transparency and cannot be fully tracked by the service provider. At the same time, all value chain stakeholders cannot experience optimal customer support, which leads to a lack of trust and inefficiency.

The UC.2 shows that the market needs to adjust very quickly to rising demand in the supply chain, and every stakeholder must be highly adaptable to respond to it. The analysis of big data helps not only solve the existing challenges but what is very important - helps to predict the upcoming pressure on the food supply chain.

When consumer needs and expectations have been estimated, every end-user is assured of the expected supply. The process becomes efficient, and the sustainability increases significantly.

The system assesses the freshness of shipped goods such as fruits, and eventually, it can be adapted for the shipment of vegetables. This means a significant reduction of spoilage and contribution to preventing food waste.

\subsubsection{Measured effectiveness of the food supply chain in the UC.2}

The real-time product monitoring brings the service quality to the next level-the pool efficiency increases by $25 \%$. The high-security level for distribution is increased by $15 \%$.

Food quality and traceability are also some of the main achievements in this use case. Improved traceability infrastructure by $50 \%$ strongly contributes to preserving product quality and increasing the supply chain system's performance.

By improving the logistics and packaging, the use case achieved an increase of food safety by $5 \%$, reducing the food waste by $5 \%$. Moreover, the service quality was raised by the quicker reaction time on real-time data, which improves by $5 \%$.

The production costs lowered - the RTI loss rate goes down to -5.5\%, and the recovery rate goes up by $80 \%$. 
DOI: $10.14807 /$ ijmp.v12i6.1748

\subsubsection{The internet of things and logistics in manufactured food - beverages supply chain}

\subsubsection{General information on the Beverage Integrity Tracking use case No.3 (UC.3)}

It prevents variability in wine quality during transportation, wine production, and management, which is supported by smart sensors that monitor everything from temperature, humidity, and shock. Tracking and monitoring go from wine producer to consumer based on the IoT system.

The logistics path from manufacturer to customer is a process that can degrade beverage quality. This use case aims to eliminate such risks by equipping the beverage supply chain stakeholders with extensive data analysis of the distribution process.

An automated system tracks the entire wine and beverage distribution chain to prevent harm from integrity-related issues during shipping and storage. Also, it develops a direct relationship between producers and retailers, and builds a vast database to schedule secure shipments, enabling new and customized IoT-based security solutions. The use case provides software as a service to monitor distribution-related variables, including temperature and humidity, to help control beverage quality.

\subsubsection{The impact made by the technology in the UC.3}

Multi-actor data analytics in the beverage industry is still an empty field. Integrity management systems have not yet been established in the same depth in this supply chain as they have in other industries. The main reason behind that is the complexity and too many stakeholders involved in the process, making it difficult to control. The provided system disrupted the supply chain with the provided capabilities to control and acquire the data.

The system which monitors beverage delivery routes and keeps a data record of every transaction brings much more transparency to the stakeholders and enables them to take full advantage of the features brought by data analytics. Data provides monitored locations and changes of the beverage containers and expands the information with environment details contained in those boxes. For the consumers becomes possible to track their wine bottle back to the winery. It gives visibility and traceability to the beverage supply chain.

\subsubsection{Supply chain management of the UC.3}

The system aims to gather much information about temperature during shipping, a shock that causes bottle ruptures, closure leakage, and the percentage of bottles with defects like cork taint, label damage, pressure loss, and oxidation. 
The database can also provide information on customer satisfaction, marketing problems, and communication effectiveness.

This data collection is beneficial for the wine and beverage industry, and it is now available to many value chain actors for the first time.

Such a supply chain management, providing quality information strengthens the relations with clients and brings a significant value for the strategic partnerships. Seeing all of the parts and pieces of the supply chain, the link is made with all the stakeholders.

This is particularly important in closing the gap between wineries and wine shops since their connection previously was the importers' responsibility.

\subsubsection{Logistics food supply chain challenges solved by the UC.3}

When delicate products, such as food or drinks, enter the supply chain, the environment with the various parameters must be strictly monitored of the proper temperature and freshness to keep the quality from the beginning point to the end-consumer.

Different stakeholders, such as producers, carriers, dealers, retailers, and insurance firms, are involved in the beverage logistics industry. Stakeholders have identified the practical issues of the everyday beverage supply processes and an impact on the system to validate the integrity of logistics. With so many stakeholders taking part in the management of the logistics in order to improve the service, many bottlenecks must be solved.

UC.3 brings lean practices into the beverage supply chain, controlling so many processes and stakeholders, it is usually very complex and complicated. In this case, used by operators, is first and foremost a tool that visually presents the documented beverage journey and serves as evidence of delivery at the goods' final destination.

Finally, it offers valuable information to help retailers understand market demands and sell the product.

The beverage supply chain experiences increased sustainability. Traceability of the beverage from the first stop to the consumer brings transparency and ensures quality products.

\subsubsection{Measured effectiveness of the food supply chain in the UC.3}

The UC.3 made a breakthrough in cost reduction and monitoring of wine and beverage quality during transport. This directly led to the improvement of the distribution conditions and 
DOI: $10.14807 /$ ijmp.v12i6.1748

an increase in the logistics' overall satisfaction. The satisfaction index (usefulness of the tool from 1(not useful) - 5 (very useful)) 4 was achieved.

Improvement in transport quality and reduction of product damages enabled to achieve the beverage supply chain's efficiency. Product returned due to damage claim was measured 5 (asked if data was useful to reduce complaints of the damage and improve product handling from 1(not useful) - 5 (very useful).

An increase in client satisfaction is 4 (asked if the tool is useful in helping to have a stronger relationship with the client from 1(not useful) - 5 (very useful)).

Connecting producers and retailers, a crucial factor which became possible due to supply chain visibility is 4 (asked if chain visibility improved with the provided data from 1 (not improved) - 5 (significantly improved)).

The system helped increase IoT user satisfaction due to improved transportation, reduced GHG emission, and reduced shipping costs.

\section{RESULTS AND DISCUSSION}

As the analysis of the pilot use cases implemented in the food supply chain revealed, the Internet of Things technology is revolutionizing logistics.

The mass connectivity of parcels to the end-consumer is enabling supply chain and logistics stakeholders to conduct real-time tracking and management decisions that increase operating performance, asset monitoring, and at the same time keeping the quality of the products and contributing to the Green Deal goals, such as reducing food waste and GHG emissions.

Table No.1 presents accumulated analysis results from all three uses cases performance indicators connected to the IoT technology.

Table 1: Summary of the results collected during the research and from the IOF2020 project

\begin{tabular}{|c|c|c|c|c|c|c|}
\hline $\begin{array}{c}\text { Di- } \\
\text { men- } \\
\text { sion }\end{array}$ & Categories & Indicators & $\begin{array}{l}\text { Technology } \\
\text { impact }^{*}\end{array}$ & $\begin{array}{c}\text { Food supply } \\
\text { chain } \\
\text { management }\end{array}$ & $\begin{array}{l}\text { Challenges } \\
\text { solved }^{* * *}\end{array}$ & Use case \\
\hline \multirow{4}{*}{ 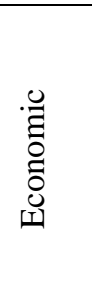 } & \multirow[t]{4}{*}{$\begin{array}{l}\text { Productivity } \\
\text { increase }\end{array}$} & Preserve product quality & Yes & Yes & Yes & $\begin{array}{l}\text { UC.2, } \\
\text { UC.3 }\end{array}$ \\
\hline & & Reduction of loss rate & Yes & Yes & Yes & UC.2 \\
\hline & & Recovery rate increase & Yes & Yes & Yes & $\begin{array}{l}\text { UC.1, } \\
\text { UC.2 }\end{array}$ \\
\hline & & $\begin{array}{l}\text { Increase security of } \\
\text { bulks-goods delivery }\end{array}$ & Yes & Yes & Yes & UC.1 \\
\hline
\end{tabular}


INDEPENDENT JOURNAL OF MANAGEMENT \& PRODUCTION (IJM\&P)

http://www.ijmp.jor.br

v. 12, n. 6, Special Edition ISE, S\&P - November 2021

ISSN: 2236-269X

DOI: 10.14807/ijmp.v12i6.1748

\begin{tabular}{|c|c|c|c|c|c|c|}
\hline & $\begin{array}{c}\text { Efficiency } \\
\text { improvement }\end{array}$ & $\begin{array}{l}\text { Reduced product return } \\
\text { due to damage claim }\end{array}$ & Yes & Yes & Yes & UC.3 \\
\hline & & $\begin{array}{l}\text { Real time product } \\
\text { monitoring }\end{array}$ & Yes & Yes & Yes & UC.2 \\
\hline & & $\begin{array}{l}\text { Increased reusability of } \\
\text { transport }\end{array}$ & Yes & Yes & Yes & UC.2 \\
\hline & & $\begin{array}{l}\text { Improve Logistics and } \\
\text { Packaging }\end{array}$ & Yes & Yes & Yes & UC.2 \\
\hline & $\begin{array}{c}\text { Cost } \\
\text { reduction }\end{array}$ & $\begin{array}{l}\text { Production costs } \\
\text { reduction }\end{array}$ & Yes & N/A & Yes & $\begin{array}{l}\text { UC.1, } \\
\text { UC.2, } \\
\text { UC.3 }\end{array}$ \\
\hline & & $\begin{array}{l}\text { Reduce additional } \\
\text { transport }\end{array}$ & Yes & Yes & Yes & UC.1 \\
\hline & & Reduce shipping costs & Yes & Yes & N/A & UC.3 \\
\hline & & Reduce recovery costs & Yes & Yes & N/A & UC.1 \\
\hline & $\begin{array}{c}\text { Quality } \\
\text { improvement }\end{array}$ & $\begin{array}{c}\text { Improve distribution } \\
\text { conditions }\end{array}$ & Yes & Yes & Yes & UC.3 \\
\hline & & Increase transport quality & Yes & Yes & Yes & UC.3 \\
\hline & & $\begin{array}{l}\text { Reduce risk of animal } \\
\text { food contamination }\end{array}$ & Yes & N/A & Yes & UC.1 \\
\hline & & $\begin{array}{l}\text { Reduce risk of human } \\
\text { food contamination }\end{array}$ & Yes & N/A & Yes & UC.1 \\
\hline & Reduced & Reduce product damages & Yes & Yes & Yes & UC.3 \\
\hline & waste & Reduce food waste & Yes & Yes & Yes & $\begin{array}{l}\text { UC.1, } \\
\text { UC.2, } \\
\text { UC.3 }\end{array}$ \\
\hline 劳 & & $\begin{array}{l}\text { Reduce waste by } \\
\text { contamination }\end{array}$ & N/A & Yes & Yes & UC.1 \\
\hline : & $\begin{array}{c}\text { Lower } \\
\text { emissions }\end{array}$ & Reduce GHG emission & N/A & N/A & Yes & $\begin{array}{c}\text { UC.1, } \\
\text { UC,2 UC.3 }\end{array}$ \\
\hline & $\begin{array}{l}\text { Resource use } \\
\text { efficiency }\end{array}$ & $\begin{array}{c}\text { Lower paper } \\
\text { documentation use }\end{array}$ & Yes & Yes & Yes & $\begin{array}{l}\text { UC.1, } \\
\text { UC.2, } \\
\text { UC.3 }\end{array}$ \\
\hline & & Facilitation of equipment & Yes & Yes & Yes & UC.2 \\
\hline & $\begin{array}{l}\text { Transparency } \\
\text { of food chain }\end{array}$ & $\begin{array}{l}\text { Increased supply chain } \\
\text { visibility and traceability }\end{array}$ & Yes & Yes & Yes & $\begin{array}{l}\text { UC.1, } \\
\text { UC.2, } \\
\text { UC.3 }\end{array}$ \\
\hline & & More data available & Yes & Yes & Yes & $\begin{array}{l}\text { UC.1, } \\
\text { UC.2, } \\
\text { UC.3 }\end{array}$ \\
\hline & & $\begin{array}{l}\text { Trust on the quality of } \\
\text { food products }\end{array}$ & N/A & Yes & Yes & $\begin{array}{l}\text { UC.1, } \\
\text { UC.2, } \\
\text { UC.3 }\end{array}$ \\
\hline تृ & $\begin{array}{c}\text { User } \\
\text { satisfaction }\end{array}$ & $\begin{array}{l}\text { Increase IoT user } \\
\text { satisfaction }\end{array}$ & Yes & Yes & Yes & $\begin{array}{l}\text { UC.1, } \\
\text { UC.2, } \\
\text { UC.3 }\end{array}$ \\
\hline & & Satisfaction index & N/A & Yes & Yes & UC.3 \\
\hline & & User satisfaction & N/A & Yes & Yes & UC.1 \\
\hline & & $\begin{array}{l}\text { Increase client } \\
\text { satisfaction }\end{array}$ & N/A & Yes & Yes & UC.3 \\
\hline & & $\begin{array}{c}\text { Connect producers- } \\
\text { retailers }\end{array}$ & Yes & Yes & Yes & UC.3 \\
\hline
\end{tabular}

*productivity, revenue growth, employment, investment; **strategic suppliers partnership, relations with clients, sharing quality information, operational lean practices; ${ }^{* * *}$ quality products, traceability, contamination, lack of trust, increased sustainability

Source: Created by authors 
DOI: 10.14807/ijmp.v12i6.1748

\subsection{Consolidating a Fragmented Infrastructure - raising effectiveness}

In notoriously complex food supply chains with the vast number of stakeholders and tons of different levels of processes turned visibility task into an unnecessarily long and drawnout process. The process that hardly anyone could take up the challenge to solve. Thousands of supply chain puzzle pieces would never fit together and, in many cases, fall apart. Or so it was until digital technologies stepped in.

As shown by the use cases achieved goals, IoT has simplified supply network management and streamlined operations and reduced operational expenses, increased quality of transportation, and connected all the players along the chain. Data was the missing puzzle piece to set everything in order. The pilot cases reduced the number of supply chain management components.

As a result, operational costs are being reduced even while food and beverage production capacity is growing. Digitalization experts stated that IoT technology is expected to significantly impact logistics in the food supply chain by reducing operational costs by at least 50 percent over the next five years and helping double the shipping amounts.

IoT technology is driving the agri-food sector towards greater collaboration. The potential of food supply chains as full-scale collaborative ecosystems is vast. The digitalized distribution system transforms the food supply chain into secured, based on providing outstanding and precise data in a highly scalable manner for every player and helping the emergence of innovative business models reliant on big data. The knowledge obtained from such a single network enables stakeholders to improve supply chain productivity.

\subsection{Improving Security, Transparency, and Traceability}

As described by the experts and based on the use case findings, food traceability and transparency of the whole food supply chain are among the most significant issues in the agrifood sector. The traceability in food supply chain logistics is referred to the availability to collect the data and ensure the quality of the final product. It means that data needs to be collected, analyzed, and deliver correct information about the food, feed, food manufacturing process at all stages of the food supply chain. This allows the product to be certified, for example, as an organic or checked for quality and safety control, also traced through all the food supply chain.

The amount of data that systems can gather and manage is unforeseen. A logistics manager can access the dashboard at any time to get real-time updates on the exact location of an asset, its distance, and its expected time of arrival based on actual travel conditions. These 
DOI: 10.14807/ijmp.v12i6.1748

real-time warnings help players in the food supply chain to stay flexible and adapt quickly through a dynamic transportation network. Delays in the supply chain can often cause significant losses, but logistic managers acquire the knowledge they need to mobilize quickly. Due to IoT technology, usually, an expensive disturbance transforms into a temporary issue.

If any food and beverage product require special handling or temperature control, geolocation capabilities can be coupled with transportation conditions monitoring for added value. The manager is also alerted if an asset falls outside a predetermined temperature range or receives unexpected vibrations or shocks.

As interconnectivity is becoming the logistics sector's practice, the industry must recognize the value of digital security. Connected systems help monitor all objects, asset tracking logistics applications help monitor deliveries, warn the management team if anything is missing, increase the transparency of who visits the warehouses at any given time, and more.

Since anything from rising temperatures in containers to security breaches can be tracked remotely, IoT technology reduces the need for physical supply chain supervision. The Internet of Things is changing security by allowing for more open supply chain solutions. On the other hand, technology is widening the digital space and increasing the need for data protection.

\subsection{Creating a Greener Supply Chain}

With the ambitious goals being set up in Green Deal, IoT technology comes as one tool to help achieve them.

As presented by the use cases, there is no doubt that the demand for environmentally sustainable logistics in the food value chain is expanding and will grow in the coming years. That means environmental concerns should be at the core of every food supply chain stakeholder plan. Although there is no one solution to the climate problem, the Internet of Things helps reduce the agri-food industry's environmental footprint by making the logistics processes smarter.

Food chain logistics stakeholders can use data collection, analysis, and machine learning to forecast traffic flow and reduce the number of unused trailers, boxes, etc., on the road at any given time. This strategy not only reduces the cost it also lowers total carbon emissions.

The transparency provided by IoT technologies significantly aids in the reduction of food waste and goods loss and damage. This is particularly valid for perishable products such 
DOI: 10.14807/ijmp.v12i6.1748

as fruits, vegetables, etc. The systems help for better cargo control and establish leaner, more effective food supply chain logistics processes as a whole.

Making the processes automated, controlled, and visible, a new path is created to a leaner and greener food supply chain. The transformational potential for the IoT in the logistics food supply chain, making it sustainable, is undeniable.

\section{CONCLUSIONS AND RECOMMENDATIONS}

IoT-connected sensors and systems in food and beverage supply chain logistics offer real-time visibility and data-driven analytics, allowing stakeholders to improve performance, cut operating costs, conduct predictive maintenance to avoid downtime, and even decrease energy usage or reduce negative environmental impacts.

With the responsibility on the logistics in the agri-food sector to fulfill two-day, overnight, or even same-day service obligations and at the same time to trace the origin and keep the quality of the products unaltered, the Internet of Things is a crucial component in assisting players in meeting the demands of today's fast-paced, global economy.

The pilot use cases in the agri-food sector have demonstrated many ways the IoT technologies can transform food supply chain logistics from the ground.

Management of the supply chain processes is better regulated, and as a result, production risks are reduced. The ability to predict performance levels accounts for improved product delivery planning.

A vast number of the data is being collected by smart sensors using IoT technologies. This information can be used to monitor all stakeholders' overall efficiency in agri-food supply chains and their employee results, equipment quality, and more.

Agri-food industry logistics cost management and significant food waste reduction are possible due to increased control over the supply chains. Being able to see any disruptions in traffic flow or quality or risks of the contamination in the goods, stakeholders can take measures to lower or avoid losses.

IoT through automation and machine learning helps increase efficiency down the supply chain. Using smart devices comes the opportunity to automate multiple processes and significantly lower the physical supervision.

Keeping the product quality and at the same time not lowering the volumes of production becomes a usual process. Better control over the logistics process helps maintain 
INDEPENDENT JOURNAL OF MANAGEMENT \& PRODUCTION (IJM\&P)

http://www.ijmp.jor.br

v. 12, n. 6, Special Edition ISE, S\&P - November 2021

ISSN: 2236-269X

DOI: $10.14807 /$ ijmp.v12i6.1748

higher standards for food and beverage quality and the production growth capacity through the whole food and beverage supply chain.

A result of applying the Internet of Things technologies to the food and beverage supply chain logistics processes leads to higher revenue for all the stakeholders.

\section{REFERENCES}

Arshinina, P., \& Kiseleva, A. (2020). Evaluation of the Effectiveness of the Logistics System. 10.2991/aebmr.k.200509.087.

Bertodo, R. (2002). Some Developing Trends in Manufacture- Supplier Relationship, International Journal of manufacturing technology and Management, 4(12), p. 21-35.

Beske, P., Land, A., \& Seuring, S. (2014). Sustainable supply chain management practices and dynamic capabilities in the food industry: A critical analysis of the literature.

International Journal of Production Economics, 152, 131-143.

https://doi.org/10.1016/j.ijpe.2013.12.026

Chen, I. J., \& Paulraj, A. (2004). Towards a theory of supply chain management: the constructs and measurements. Journal of operations management, 22(2), 119-150.

Croom, S., Vidal, N., Spetic, W., Marshall, D., \& McCarthy, L. (2018). Impact of social sustainability orientation and supply chain practices on operational performance.

International Journal of Operations \& Production

Management. https://doi.org/10.1108/IJOPM-03-2017-0180

Da Xu, L., He, W., \& Li, S. (2014). Internet of things in industries: A survey. IEEE Transactions on industrial informatics, 10(4), 2233-2243.

Emamisaleh, K., \& Rahmani, K. (2017). Sustainable supply chain in food industries: Drivers and strategic sustainability orientation. Cogent Business \& Management, 4(1), 1345296. https://doi.org/10.1080/23311975.2017.1345296

Emamisaleh, K., Rahmani, K., \& Iranzadeh, S. (2018). Sustainable Supply Chain Management Practices and Sustainability Performance in the Food Industry. The South East Asian Journal of Management. https://doi.org/10.21002/seam.v12i1.8689

European Commision (2020). Farm to Fork Strategy: For a fair, healthy and environmentally-friendly food system.

European Commission (2020). CORDIS. Horizone2020, Internet of farms project. https://cordis.europa.eu/project/id/731884

European Commission (2020). Strategy, Shaping Europe's digital future.

https://ec.europa.eu/digital-single-market/en/large-scale-pilots-digitisation-agriculture

Felea, Mihai \& Albastroiu, Irina. (2013). Defining the Concept of Supply Chain Management and its Relevance to Romanian Academics and Practitioners. Amfiteatru Economic, 15, 7488.

Hall, D., Jones, R., Raffo, C., Andertonб, A., Chambers, I., \& Gray, D. (2008). Business studies: Teachers guide (4th ed.), Harlow, Essex: Pearson Education, 2008.

Hult, G. T. M., Ketchen, D. J., \& Arrfelt, M. (2007). Strategic supply chain management: Improving performance through a culture of competitiveness and knowledge

development. Strategic management journal, 28(10), 1035-1052. 
Ibrahim, S. B., \& Hamid, A. A. (2014). Supply chain management practices and supply chain performance effectiveness. International Journal of Science and Research, 3(8), 187-195.

Jain, J., Dangayach, G. S., Agarwal, G., \& Banerjee, S. (2010). Supply Chain Management: Literature Review and Some Issues. Journal of Studies on Manufacturing, 1(1), 11-25.

Kang, H. S., Lee, J. Y., Choi, S., Kim, H., Park, J. H., Son, J. Y., Kim, B. H. \& Noh., S. D. (2016). Smart Manufacturing: Past Research, Present Findings, and Future Directions.

International Journal of Precision Engineering and Manufacturing-Green Technology, 3 (1), 111-128.

Kilimis P., Zou W., Lehmann, M., \& Berger, U. (2019). A Survey on Digitalization for SMEs in Brandenburg, Germany, IFAC-PapersOnLine, 52 (13), 2140-2145. Logistics

Management, 41 (1), p. 16-31.

López-Morales, J. A., Martínez, J. A., \& Skarmeta, A. F. (2020). Digital Transformation of Agriculture through the Use of an Interoperable Platform. Sensors, 20(4), 1153. MDPI AG. Retrieved from http://dx.doi.org/10.3390/s20041153

Lozano, J., Saenz-Diez, C., Martinez, E., Jiménez, E., \& Blanco, J. (2017). Integration of the SMED for the improvement of the supply chain management of spare parts in the food sector. Agricultural Economics (Zemědělská ekonomika). 63. 10.17221/69/2016-AGRICECON.

Mathur, B., Gupta, S., Meena, M. L., \& Dangayach, G. S. (2018), Healthcare supply chain management: literature review and some issues. Journal of Advances in Management Research, 15(3), 265-287. https://doi.org/10.1108/JAMR09-2017-0090

Mckinnon, A. C., Browne, M., \& Whiteing, A. (2012). Green Logistics: Improving the Environmental Sustainability of Logistics. Kogan Page Publishers, London.

Mogaka, C., Njiru, K., \& Arani, W. (2020). Supply chain management practices as a competitive tool for third party logistics providers performance. Journal of Sustainable Development of Transport and Logistics, 5(2), 143-152. doi:10.14254/jsdtl.2020.5-2.13

Movahedi, B., Lavassani, K., \& Kumar, V. (2009). Transition to B2B e-Market place Enabled Supply Chain: Readiness Assessment and Success Factors". The International Journal of Technology, Knowledge and Society, 5 (3), 75-88.

Oettmeier K., \& Hofmann, E. (2016). Impact of additive manufacturing technology adoption on supply chain management processes and component. Journal of Manufacturing Technology Management, 944-968. DOI: https://doi.org/10.1108/jmtm-12-2015-0113.

PWC report, https://www.gsma.com/iot//wp-content/uploads/2013/02/Connected-life-lowres-210213.pdf.

Renda, A., Reynolds, N., Laurer, M., \& Cohen, G. (2019). CEPS and BCFN "Digitising Agrifood: Pathways and Challenges.

Rotz, S., Gravely, E., Mosby, I., Duncan, E., Finnis, E., Horgan, M., \& Fraser, E. (2019). Automated pastures and the digital divide: How agricultural technologies are shaping labour and rural communities. Journal of Rural Studies, 68, 112-122.

Rushton, A., Croucher, P., \& Baker, P. (2014). The Hand Book of Logistics \& Distribution Management (5th ed.), London: Kogan Page.

Russmann, M., Lorenz, M., \& Gerbert, P (2015). Industry 4.0. The Future of Productivity and Growth in Manufacturing Industries. 
Salampasis, M., \& Theodoridis, A. (2013). Information and Communication Technology in Agricultural Development Preface. Procedia Technology, 8, 1-3.

Sarni, W., Mariani, J., \& Kaji, J. (N/D). From Dirt to Data: The Second Green Revolution and IoT. Deloitteinsights. Available online:

https://www2.deloitte.com/insights/us/en/deloitte-review/issue-18/second-green-revolutionand-internet-of-things.html\#endnote-sup-9 Accessed on 01 March 2020.

Schwab, K. (2016). The Fourth Industrial Revolution: what it means, how to respond, World Economic Forum, 2016.

Tyapuhin, A. P. (2007). Designing commodity distribution systems based on logistics: studies allowance, Moscow: Finance and Statistics.

Tzounis, A., Katsoulas, N., Bartzanas, T., \& Kittas, C. (2017). Internet of Things in agriculture, recent advances and future challenges. Biosyst,164, 31-48.

Ulas, D. (2019). Digital Transformation Process and SMEs. Procedia Computer Science, 158, 662-671.

Varsei, M., Soosay, C., Fahimnia, B., \& Sarkis, J. (2014). Framing sustainability performance of supply chains with multidimensional indicators. Supply Chain Management: An

International Journal. DOI: https://doi.org/10.1108/SCM-12-2013-0436.

Villa-Henriksen, A., Edwards, G. T. C., Pesonen, A. L., Green, O., \& Sørensen C. A. G. (2020) Internet of Things in arable farming: Implementation, applications, challenges and potential, Biosystems Engineering, 191, 60-84. DOI:

https://doi.org/10.1016/j.biosystemseng.2019.12.013.

Wajszczuk, K. (2016). The Role and Importance of Logistics in Agri-Food Supply Chains: An Overview of Empirical Findings. Logistics and Transport, 30, 47-55. 